\title{
A Study on Factors Associated with Clomifene Resistance in Infertile Women with WHO Group II Anovulation at a Teaching Hospital in Sri Lanka
}

\author{
Palihawadana TS ${ }^{1}$, Dissanayake DMAB ${ }^{1}$, Wijesinghe $\mathrm{PS}^{1}$, Seneviratne $\mathrm{HR}^{2}$
}

\begin{abstract}
Background: Anovulation is a common cause of infertility and induction of ovulation with oral agents such as clomifene is the treatment of choice in women with normogonadotropic anovulation. While such treatment is able to achieve ovulation in many, some women fail to respond thus termed as having clomifene resistance. Knowledge on factors associated with such resistance would enable us to counsel patients more accurately and offer alternative treatment modalities without undue delays. This study was aimed at identifying factors associated with clomifene resistance among infertile women with WHO group II anovulation at a teaching hospital in Sri Lanka.
\end{abstract}

Method: A case control study was done at the Infertility clinic of the North Colombo teaching hospital, Ragama conducted by the department of obstetrics \& Gynaecology of the University of Kelaniya. Women with WHO group II anovulation $(n=128)$ were included and underwent induction of ovulation with clomifene citrate starting at a dose of $50 \mathrm{mg}$ per day, increased up to $150 \mathrm{mg}$ till ovulation was achieved. Those who fail to respond to a maximum dose of $150 \mathrm{mg}$ were termed as clomifene resistant. The factors known to be associated with clomifene resistance were compared between the two groups who responded and those who failed to respond. The study was registered with the Sri Lankan clinical trial registry maintained by the Sri Lanka Medical association. The study was funded by the National Science foundation of Sri Lanka through a research grant (Grant No: RG/2007/HS/08)

Results: Ovulation was achieved in $77.3 \%(n=99)$ of subjects and therefore the prevalence of clomifene resistance was $22.8 \%(n=29)$. Among those who responded, 41 did so at a dose of $50 \mathrm{mg}$ per day while $40 \%$ did with $100 \mathrm{mg}$, thus over $80 \%$ achieving ovulation at a dose of $100 \mathrm{mg}$ per day or less. The factors associated with clomifene resistance in this population included infertility of more than three years (OR $2.06,95 \% \mathrm{Cl} 1.51-9.14)$, presence of hirsutism (OR 2.76, 95\% $\mathrm{Cl} 1.18-6.46$ ), a higher AFC (16 vs 13, p=0.04), PCOS (OR 2.99, $95 \% \mathrm{Cl} 1.06-8.41)$ and an $\mathrm{LH}: \mathrm{FSH}$ ratio of $>1(\mathrm{OR} 3.11,95 \% \mathrm{Cl} 1.33-7.24)$. Other factors that have been described to be associated with clomifene resistance such as advanced age, a $\mathrm{BMI}>25$, and a higher ovarian volume did not show any significant associations in this study.

Discussion: This study was able to identify factors associated with clomifene resistance in a local population. Most factors identified included clinical and laboratory findings of PCOS thus highlighting the limitations in treatment success of clomifene among women with PCOS. This information may be used in clinical practice to counsel patients prior to treatment or to consider other alternative treatment options such as Letrozole or gonadotropins.

\section{INTRODUCTION}

Anovulation is the commonest cause of female infertility ${ }^{1}$ and is seen in approximately $20-30 \%$ of couples ${ }^{2,3}$.

\footnotetext{
1 Faculty of Medicine, University of Kelaniya

2 Faculty of Medicine, University of Colombo
}

Correspondence: Dr. T.S. Palihawadana

E-mail: thilipali@kln.ac.lk

Competing interests: None
The WHO classification defines WHO group II anovulation as anovulation in the presence of normal levels of gonadotropins. Polycystic ovary syndrome (PCOS) makes up nearly $70 \%$ in this group 4 . The mainstay in treatment of infertility in this group is induction of ovulation. Clomifene citrate is the most commonly used oral ovulation induction agent worldwide. It is an anti-oestrogen, which blocks the oestrogen receptors at the level of the hypothalamus thus inducing FSH secretion from the anterior pituitary by interfering with the negative feedback of oestrogen. It is often used as the first line agent and other methods such as gonadotropins are reserved for patients who do not respond to clomifene citrate or fail to conceive with such treatment.

While it is an effective therapeutic agent in achieving ovulation in approx. $60-85 \%$ of cycles, pregnancy rates are much lower at $30-40 \%^{5-7}$. The discrepancy is thought to be due to the unwanted anti-oestrogenic effects of the medication on the developing endometrium and the cervical mucus. Therefore, clomifene citrate should be used at the minimum dose required to achieve ovulation. It is started at a dose of $50 \mathrm{mg}$ per day for five days at the beginning of the menstrual cycle and the dose is increased every month based on the response till ovulation achieved. If ovulation is not achieved at a maximum dose of $150 \mathrm{mg}$ per day, it is considered as clomifene resistance ${ }^{8}$.

Prediction of treatment response would enable us to identify patients who require other methods of induction of ovulation such as gonadotropins or laparoscopic ovarian drilling, in women with PCOS. This will allow the clinicians to be more informed when counselling patients about prognosis, avoid delays in achieving ovulation, and reduce overall treatment costs.

This study was aimed at assessing the incidence and identifying the factors associated with clomifene resistance among a group of infertile women with WHO group II anovulation at a teaching hospital in Sri Lanka.

\section{METHOD}

The study was carried out at the University infertility clinic of the North Colombo Teaching hospital, Ragama, Sri Lanka, conducted by 
the department of Obstetrics and Gynaecology, University of Kelaniya. A case control study design was used and included women who were diagnosed to have anovulation with normal levels of early follicular phase FSH (2-20IU/1), thus belonging to WHO group II anovulation. Women were between 18-40 years with normal levels of TSH and prolactin levels and those with any previous ovarian surgery were excluded.

All women included in the study were seen on the $2^{\text {nd }}$ day of a spontaneous menstrual cycle and the FSH and LH levels in the index cycle were done. They underwent an ultrasound scan for ovarian morphology and determination of antral follicle count (AFC). Clomifene citrate was commenced at a dose of $50 \mathrm{mg}$ per day for 5 days starting from the $2^{\text {nd }}$ day of the menstrual cycle. Ultrasound follicle tracking was commenced from the $9^{\text {th }}$ day of the cycle and continued till detection of ovulation. Absence of any dominant follicle $(>10 \mathrm{~mm}$ diameter) by the $12^{\text {th }}$ day or follicle development arrest (no increase in diameter after 3 day) was taken as anovulatory. Those who fail to ovulate with such treatment had the drug dose increased by $50 \mathrm{mg}$ per day, in the subsequent cycles till a maximum dose of $150 \mathrm{mg}$ was achieved. Failure to respond to such a maximum dose was termed as clomifene resistance.

The main outcome variables compared between the two groups included age, BMI, presence of significant hirsutism, the ovarian volume, the AFC, FSH level and an abnormal FSH:LH ratio (a ratio of $>1$ ). Hirsutism was assessed using the modified Ferriman-Gallwey scoring system with a cut off score of eight ${ }^{9}$. AFC was assessed by counting the number of follicles with a diameter of $2-9 \mathrm{~mm}$ on an early follicular phase pelvic ultrasound scan. Polycystic ovary syndrome was diagnosed according to the modified Rotterdam criteria $^{10}$. Visualisation of a mature follicle (with a diameter $>17 \mathrm{~mm}$ ) and detection of its absence in 3 days with or without other evidence of ovulation such as appearance of the corpus luteum and free fluid in the pouch of Douglas were considered as confirmation of ovulation. A single investigator (TSP) performed all ultrasound scan investigations using a GE LOGIQ 3 (GE healthcare, USA) scanner with a transvaginal transducer of 4.0-8.0 MHz.

The sample size calculation was done using previous data from a study by Imani et al, which achieved ovulation with clomifene in $77 \%$ of subjects included $^{11}$. With an acceptable difference up to $10 \%$ of the assumed incidence, a sample size of 107 was calculated using WinPepi computer software, to describe the incidence of a satisfactory response to clomifene in this population. With an estimated drop up rate up to $20 \%$ a total of 128 was included in the study.

Approval for the study was obtained from the ethics review committee of the Faculty of Medicine, University of Kelaniya prior to study commencement. The trial was registered as a clinical trial with the Clinical trials registry of Sri Lanka Medical Association, a WHO affiliated registry (SLCTR/ 2008/015).

\section{RESULTS}

The total study population included 128 women with WHO group II anovulation with a mean age of 28.3 years (95\% CI 27.5-29.1) and a mean BMI of $25.4 \mathrm{~kg} / \mathrm{m}^{2}$ (95\% CI 24.3-26.4). Polycystic ovarian syndrome was present in $85(66.4 \%)$ subjects.

\begin{tabular}{|c|c|c|c|}
\hline Factor studied & $\begin{array}{c}\text { CC resistant } \\
n=29\end{array}$ & $\begin{array}{c}\text { CC responsive } \\
n=99\end{array}$ & \\
\hline Age; mean (SD) & $28.3(4.2)$ & $28.3(5.0)$ & $p=0.969$ \\
\hline Infertility > 3yrs & 13 & 28 & $\begin{array}{c}\text { OR } 2.06 \\
(95 \% \mathrm{Cl} 1.51-9.14)\end{array}$ \\
\hline $\mathrm{BMl}>25 \mathrm{~kg} / \mathrm{m}^{2}$ & 17 & 52 & $\begin{array}{c}\text { OR } 1.28 \\
(95 \% \mathrm{Cl} 0.56-2.94)\end{array}$ \\
\hline Hirsutism & 14 & 25 & $\begin{array}{c}\text { OR } 2.76 \\
(95 \% \mathrm{Cl} 1.18-6.46)\end{array}$ \\
\hline Mean ovarian volume: $\mathrm{cm}^{3}$ & $8.46(3.19)$ & $7.57(3.37)$ & $p=0.208$ \\
\hline Mean AFC & $16.0(7.1)$ & $13.3(6.1)$ & $p=0.04$ \\
\hline PCOS & 24 & 61 & $\begin{array}{c}\text { OR2.99 } \\
(95 \% \mathrm{Cl} 1.06-8.41)\end{array}$ \\
\hline LH:FSH>1 & 17 & 31 & $\begin{array}{c}\text { OR } 3.11 \\
(95 \% \text { Cl } 1.33-7.24)\end{array}$ \\
\hline Expressed as no (\%) unless & ned. Signific & issociations are sl & own in bold \\
\hline
\end{tabular}

Induction of ovulation was successful in $99(77.3 \%)$ of subjects. They included $41(32 \%)$ who ovulated at a dose of $50 \mathrm{mg}$ per day, $40(31 \%)$ at $100 \mathrm{mg}$ and $18(14 \%)$ with a dose of $150 \mathrm{mg}$. Incidence of Clomifene resistance was

A comparison of predictive factors for clomifene citrate between the subjects who responded and were resistant is shown in table1.

\section{DISCUSSION}

Induction of ovulation is a common procedure undertaken in management of infertility and is offered to many patients either alone or in combination of intrauterine insemination. Clomifene citrate remains to be the most commonly used agent worldwide. Though previous studies have been done on predictive factors of treatment success in use of clomifene among WHO group II anovulation, not many studies have been done in local populations.

The study population included in this study had a PCOS prevalence of $66 \%$, and is similar to prevalence described in other studies ${ }^{4}$. Ovulation was achieved with clomifene in approximately three quarters of the subjects. This was comparable with studies done in other countries ${ }^{5}$. In women who responded, nearly $80 \%$ did so at a dose of $100 \mathrm{mg}$ per day $23 \%$ in this study group. 
or less. The incidence of clomifene resistance was $22 \%$.

The factors associated with clomifene resistance in our study population included a longer duration of infertility ( $>3$ years), presence of hirsutism, PCOS, a higher AFC count and an LH:FSH ratio of $>1$. Researchers in other countries have also described these ${ }^{11}$. Among these an abnormal LH:FSH ratio showed the strongest correlation where women with such hormone abnormality are three times more likely to be resistant to clomifene. Most features associated with clomifene resistance are clinical and laboratory findings associated with PCOS thus indicating the limitations of its use in this condition. These findings are useful in patient counselling and predicting treatment success in women who present with infertility associated with WHO group II anovulation.

Newer therapeutic agents such as Letrozole, a third generation aromatase inhibitor, has been proposed as an alternative to clomifene in induction of ovulation in recent times ${ }^{12}$. While many use it as second line agent in clomifene resistance or treatment failure in spite of achieving ovulation, many argue that it should be a potential alternative to clomifene as a first line agent. However, its place in management protocols has not been clearly established ${ }^{13}$. This debate, which has been ongoing for some time, was swayed in favour of Letrozole with recent publications of a well conducted adequately powered study which demonstrated it to be superior to clomifene in women with PCOS $^{14}$. This may partly be due to the limitations of clomifene in women with PCOS as seen in our study. Though the clinical use of Letrozole was cautioned following a small study, which demonstrated a higher rate of congenital anomalies with its use $^{15}$, later studies did not support this hypothesis. Furthermore, as it has a very short half-life (45 hours), it is very unlikely to have adequate amounts of blood levels at the time of conception to cause any teratogencity. Therefore, its use mong women with above factors associated with clomifene resistance should be considered and further research on the use of Letrozole in such women should be undertaken. Early conversion to gonadotropin is also an alternative in such women.

This study had its own limitations. Firstly, we were not able to see the effect of factors such as age and BMI on treatment response to clomifene as the study population was relatively young (mean 28.3 years; 95\% CI 27.5-29.1) and with a normal BMI (mean $25.4 \mathrm{~kg} / \mathrm{m}^{2}$; 95\% CI 24.3-26.4). Both these factors have shown to be associated with Clomifene resistance in previous studies.

\section{ACKNOWLEDGEMENTS}

This study was funded by the National Science Foundation (NSF) of Sri Lanka through a research grant (Grant no RG/2007/HS/08).

\section{REFERENCES}

1. Evers JL. Female subfertility. Lancet 2002; 360: 151-9.

2. Hull MG, Glazener CMA, Kelly NJ, et al. Population study of causes, treatment, and outcome of infertility. British Medical Journal (Clinical research ed) 1985; 291: 1693.

3. Hamilton-Fairley D, Taylor A. Anovulation. BMJ 2003; 327: 546-9.

4. Adamson GD, Baker VL. Subfertility: causes, treatment and outcome. Best Practice \& Research Clinical Obstetrics \& Gynaecology 2003; 17(2): 169-85.

5. Kousta E, White DM, Franks S. Modern use of clomiphene citrate in induction of ovulation. Hum Reprod Update 1997; 3: 359-65.
6. van Santbrink EJP. Is there a future for ovulation induction in the current era of assisted reproduction? Human Reproduction 2003; 18: 2499-502.

7. Lambalk CB, Huirne JAF, Macklon NS, et al. Ovulation induction with clomiphene or gonadotropins. International Congress Series 2005; 1279: 16-23.

8. National Collaborating Centre for Women's and Children's Health. Fertility: assessment and treatment for people with fertility problems. NICE clinical guideline. RCOG press, London. 2013:1-562.

9. Archer JS, Chang RJ. Hirsutism and acne in polycystic ovary syndrome. Best Pract Res Clin Obstet Gynaecol 2004; 18: 737 54.

10. Rotterdam ESHRE/ASRM-Sponsored PCOS consensus workshop group. Revised 2003 consensus on diagnostic criteria and long-term health risks related to polycystic ovary syndrome (PCOS). Hum Reprod 2004;19: 41-7.

11. Imani B, Eijkemans MJ, Velde te $E R$, et al. Predictors of chances to conceive in ovulatory patients during clomiphene citrate induction of ovulation in normogonadotropic oligoamenorrheic infertility. Journal of Clinical Endocrinology \& Metabolism 1999; 84:1617-22.

12. Casper RF. Aromatase Inhibitors for Ovulation Induction. Journal of Clinical Endocrinology \& Metabolism 2005; 91 : 760-71.

13. Casper RF, Mitwally MFM. A historical perspective of aromatase inhibitors for ovulation induction. Fertil Steril 2012; 98: 1352-5.

14. Legro RS, Brzyski RG, Diamond MP, et al. Letrozole versus clomiphene for infertility in the polycystic ovary syndrome. N Engl J Med 2014; 371: 119-29.

15. Biljan MM, Hemmings $R$, Brassard $N$. The Outcome of 150 Babies Following the Treatment With Letrozole or Letrozole and Gonadotropins. Fertil Steril 2005; 84: S95. 